\title{
Implementation of the precautionary principle in standards for the workplace
}

\author{
Anne Stijkel, Lucas Reijnders
}

\begin{abstract}
The objectives were to describe and discuss the current and proposed European occupational health policy on two categories of substances that pose serious effects: those potentially carcinogenic or genotoxic and those with toxic effects on reproduction. The precautionary principle was applied to setting standards for the workplace for those two categories of substances, to give an impression of the resulting limit values and the consequences of the implementation of this precautionary principle. A pragmatic approach was chosen as this starts with substantial indications of health risks. For the suspected carcinogenic or genotoxic substances $0.1 \mathrm{mg} / \mathrm{m}^{3}$ as a precautionary occupational exposure limit (precautionary $(\mathrm{OEL})$ is proposed. For the substances suspected of causing reproductive toxicity the precautionary OEL was derived in three ways, depending on the availability of data and of a current Dutch workplace standard (MAC, maximum accepted concentration): ( $a$ ) by calculation based on available inhalatory animal data on the risks of reproductive toxicity; (b) by adding a safety factor of 10 to the current MAC, if no inhalatory animal data on reproductive toxicity are available; (c) by using $0.1 \mathrm{mg} / \mathrm{m}^{3}$ as precautionary OEL for substances suspected of having reproductive toxicity but without inhalatory animal data on reproductive toxicity and without a MAC.
\end{abstract}

(Occup Environ Med 1995;52:304-312)

Utrecht University,

Department of

Science, Technology, and Society,

Padualaan 14, 3584CH

Utrecht, The

Netherlands

A Stijkel

University of

Amsterdam,

Interfaculty

Department of

Environmental

Sciences, Nieuwe

Prinsengracht 130,

$1018 \mathrm{VZ}$ Amsterdam,

The Netherlands

L Reijnders

Correspondence to:

Dr Anne Stijkel, Utrecht

University, Department of

Science, Technology, and

Society, Padualaan 14,

3584CH Utrecht,

The Netherlands.

Accepted 19 January 1995 substances. We discussed these points in more detail in the companion article in this Fournal. g term effects-for example cinogenesis, genotoxicity, and reprodu fournal.

Keywords: precaution; reproductive toxicity; safety protection is given if data are lacking. Also, detail in the companion article in th

The current approach to setting workplace standards has been criticised in the past from different angles. One of the comments con-
cerned the use of the rationale that if there is no evidence of impairment, no safety factors
Several solutions are conceivable. An approach fundamentally different from the current one (as long as harm is not proved, risks are not considered likely) is "the reversal of the burden of proof": every exposure to a substance is considered dangerous, until the extent of toxicity is sufficiently known. According to the risk classifications, ${ }^{23}$ also described in the preceding article, ${ }^{1}$ this type of risk attitude can be characterised as the attitude of risk avoidance, to be distinguished from the attitudes of risk regulation and risk acceptance.

In The Netherlands, for many years scientists and trade union representatives have criticised the existing workplace exposure standards. ${ }^{4}$ After the 1992 United Nations conference on environment and development (UNCED) in Rio de Janeiro, Brazil, this criticism was re-emphasised by a very broad range of social movements. More than 50 Dutch environmental, health, women's, and trade union organisations have joined forces and twice appealed to the government to use the precautionary principle in setting standards in the workplace. This approach, they claimed, would protect the quality of the children and prevent irreversible effects such as cancer. ${ }^{56}$ These organisations made a case for the introduction of the principle that potentially toxic substances should be banned, unless the extent of toxicity to men, women, children, and fetuses was sufficiently known to derive a standard.

Considering the comments on today's practices of setting standards in which the attitudes of risk regulation and risk acceptance are so apparent, we explore here an approach for setting standards for occupational exposure that fits the attitude of risk avoidance, by using the precautionary principle. So, the central question is: How can the precautionary principle be implemented in occupational exposure standards, and what might be the resulting limit values?

The precautionary principle was adopted internationally as a starting point for environmental policy in 1992 at the global UNCED in Rio de Janeiro, Brazil. This principle stipulates that "where there are threats of serious or irreversible environmental damage, lack of full scientific certainty shall not be used as a reason for postponing cost effective measures to prevent degradation". ${ }^{7}$

The way in which the various concepts (threats, serious damage, certainty, cost effectiveness) within the description of the precautionary principle should be interpreted could 
be extensively discussed, analogous to the concepts discussed in our companion article. Here we have chosen a more practical approach to give an impression of the consequences when interpreting the concepts in one specific way. The concept of cost effective measures is not included in our elaboration. The reason for this choice is that the Dutch legislation distinguishes two criteria in preventing harm to health: effectiveness in prevention of health injury and reasonableness of measures. According to that framework, discussion about the cost effectiveness fits within the discussion about reasonableness of measures (see also the preceding article ${ }^{1}$ ). So, here attention is given to only the first criterion considered from the viewpoint of the precautionary principle.

Which substances can cause serious or irreversible harm in occupational situations? Besides national and European lists with occupational exposure limits, intended to prevent some kind of harm, several other lists with substances that potentially cause serious or irreversible harm are presented in scientific literature or in policy documents. Important lists may be those derived from the EU directive about the classification of hazardous substances. ${ }^{8}$ This directive was adapted regularly by amendments on new categories or classification of new substances. The last amendment was passed in $1993 . .^{9}$ Some categories of this directive are especially important in the application of the precautionary principle for two important categories of workplace toxicants: those potentially carcinogenic or genotoxic and those substances with toxic effects on reproduction. Both categories are considered to have potentially serious and irreversible effects. International policy is under debate for carcinogens and substances toxic to reproduction. ${ }^{1011}$ Before discussing how to apply the precautionary principle to the workplace, we first describe and discuss the recent developments in the European policy on setting standards for carcinogens and substances with reproductive toxicity.

According to the EU directive on carcinogens, ${ }^{10}$ companies have to register substances designated by R45 (may cause cancer), as well as some drugs, food additives, and cosmetics. The company's register is open to employers, employees, Occupational Health and Safety services, and governmental control bodies. Moreover, the employer has to assess the extent of risk for his workers. Exposure limits, to be drafted by the EU Council, will be published in an appendix to the directive at a later date. In The Netherlands, the Arboraad, an advisory board for the Dutch Minister of Social Affairs and Employment, proposed to separate the standards for genotoxic carcinogens from current traditional occupational exposure limits (OELs) (in The Netherlands these OELs are called maximum accepted concentrations or MACs), because a mortality risk is accepted when a standard for a genotoxic carcinogenic substance exceeds zero. In principle, this is not the case in standards for non-carcinogenic substances, which claim to prevent health injury and mortality. For that reason, the Arboraad introduced the term technical limit concentrations (TLC values) for genotoxic carcinogens. Preconditions for using TLCs are (a) the availability of measuring methods and strategies; $(b)$ the principle to keep exposure as low as reasonably achievable; and (c) justification for using a genotoxic agent. ${ }^{12}$ In Germany standards have already been set for this category of substances. ${ }^{13}$

Only one EU directive, "pregnant and lactating workers" is available on reproductive policy. ${ }^{11}$ According to this directive, employers are required to evaluate the risks especially from exposure to specifically listed substances on the safety and health of their workers who fit into these categories.

For genotoxic or carcinogenic substances, setting of standards is still being developed. The European governments still have to decide which type of exposure limits for genotoxic carcinogens should be introduced. Apart from the directives and standards about asbestos, vinyl chloride monomer, and benzene(-derivatives) actual exposure limits have not yet been set in the EU. The proposed strategy for setting standards in The Netherlands, based on a maximum accepted risk, combines the risk acceptance and the risk regulation attitudes. For substances with toxic effects on reproduction the European policy deals with only one aspect of the reproductive toxicity problem: the developmental risks through women to progeny. For the other reproductive risks to men and women no policy has been developed, despite the new " $R$ " sentences on risks. No approach for developing adequate standards for reproductive risks is given.

\section{Methods}

Considering the comments on the current standards and the developments in the setting of standards for carcinogens and substances with reproductive toxicity, it seems worthwhile to investigate how to implement the precautionary principle in setting occupational standards. Consequently, we offer a method to develop precautionary OELs, and present examples of them.

The concept of the precautionary principle leaves space for interpretation. Here we elaborate upon it from a realistic perspective of avoidance of risk by concentrating on serious effects and starting with substances with current indications of risk, as presented in policy documents or in peer reviewed literature. We illustrate the applicability of the precautionary principle for two important categories of workplace chemicals that are generally considered to have serious effects: those potentially carcinogenic or genotoxic, and those with potentially toxic effects on reproduction (figure).

CARCINOGENIC OR GENOTOXIC SUBSTANCES We considered the substances rated as R45 (can cause cancer) and R46 (can cause genetic harm) according to the most recent 


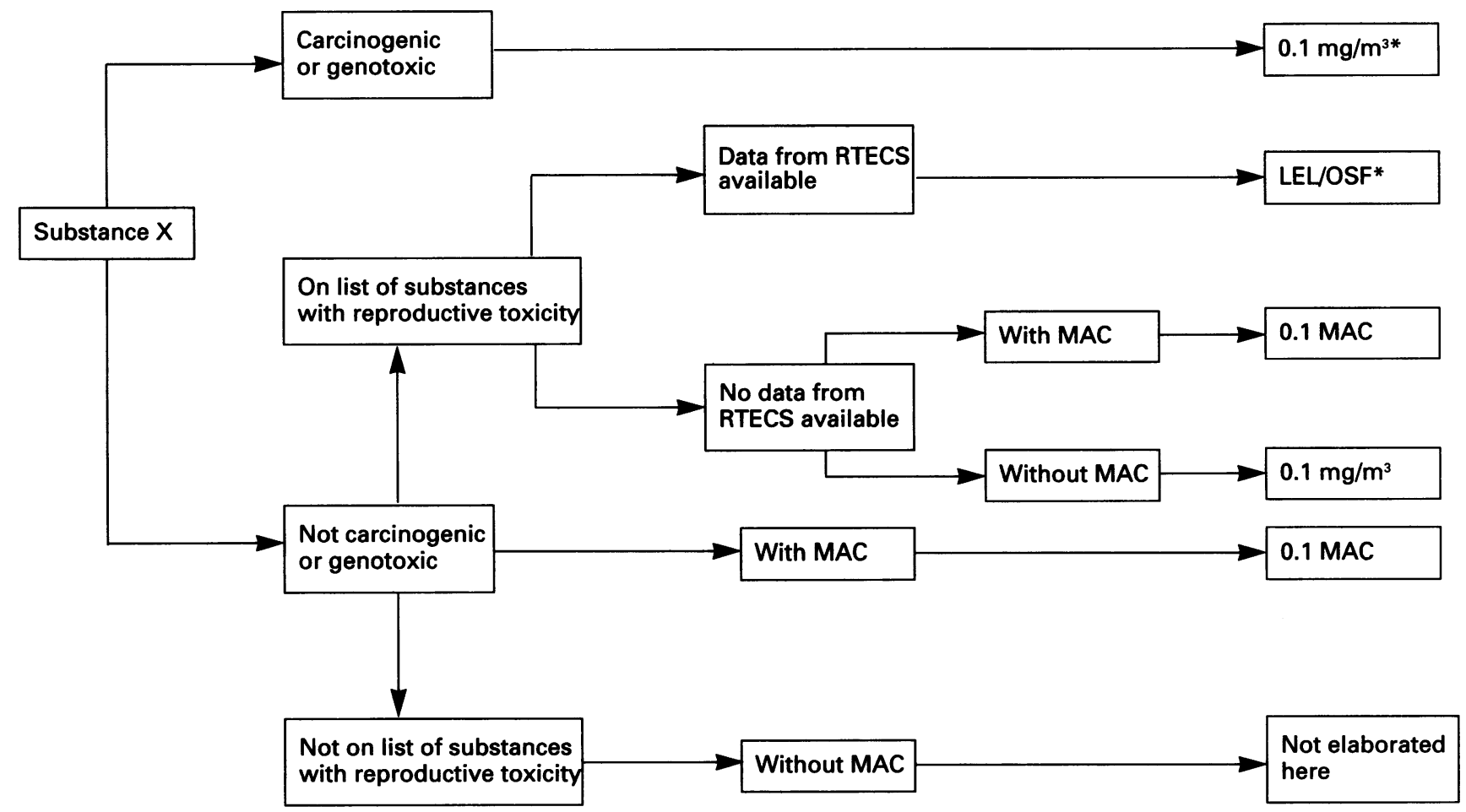

Standard setting strategy for occupational exposure standards, based on the precautionary principle. MAC = maximum accepted concentration; $R T E C S=$ inhalatory data on reproductive toxicity in the registry of toxic effects of chemical substances; $L E L=$ lowest effect level for reproductive toxicity, as indicated in RTECS; OSF = overall safety factor. *If LEL/OSF >0.1 MAC, $0.1 M A C$ is the proposed precautionary OEL, because of the limitations of the RTECS database.

EU classification of hazardous substances. ${ }^{9}$ Because the Dutch government policy on carcinogenic and genotoxic substances is more comprehensive as it is updated each half year, we have used the Dutch list. ${ }^{14}$

We limited ourselves to the separate substances and excluded those that as yet are only suspected as a group. The Dutch order, based on the EU directive, carcinogens, mentions four groups: beryllium compounds, chromium VI compounds, polycyclic aromatic hydrocarbons, and aromates of fuels. For substances that belong to these groups the generic strategy proposed here may be followed.

Except for a few substances, in the EU no standards are yet provided for genotoxic or carcinogenic substances, but it is generally accepted that for these substances a "no effect level" (NEL) does not exist. As yet, only Germany has developed a list with TLCs. ${ }^{13}$ The strictest implementation of the precautionary principle in the workplace would mean an exposure limit of zero. In fact, however, we propose that for these substances a precautionary OEL of $0.1 \mathrm{mg} / \mathrm{m}^{3}$ as a ceiling value should be established as long as other more far reaching measures are not possible and if the use of the substance is justified. Exposure should be kept as low as reasonably achievable below this level. For some specific substances in Europe more far reaching regu- lations exist-for example, for asbestos and benzene. Sometimes the current OEL is lower than $0.1 \mathrm{mg} / \mathrm{m}^{3}$ - for example, for vinylchloride monomer. Obviously, in those cases, the more far reaching regulation should be used.

To use a generic ceiling value not primarily based on toxicological motives, stems from the practice used in setting standards for quality of drinking water in The Netherlands. For substances that do not occur naturally in the environment, a value of $0.1 \mu \mathrm{g} / 1$ was set. ${ }^{15}$ This value was chosen without a basis of toxicological data.

The generic value of $0.1 \mathrm{mg} / \mathrm{m}^{3}$ was also chosen arbitrarily. If we compare this value with the current Dutch OELs $(n=642)$, we see that $10 \%$ of them are equal to or lower than that value. From that perspective 0.1 $\mathrm{mg} / \mathrm{m}^{3}$ is a value at the lower limit. On the other hand, if we compare this value with the current German TLC values established so far for carcinogenic substances $(n=64)$, again much lower values were seen ( 21 values lower than $0 \cdot 1 \mathrm{mg} / \mathrm{m}^{3}$; nine values equal to $0.1 \mathrm{mg} / \mathrm{m}^{3} ; 34$ values higher than $0.1 \mathrm{mg} / \mathrm{m}^{3}$ ). The specific German values, as far as available, may be adopted.

\section{SUBSTANCES WITH TOXIC EFFECTS ON} REPRODUCTION

Those substances that do not belong to the category of carcinogenic or genotoxic sub- 
stances, but are suspected of causing reproductive risks make up this category. It includes the remaining substances from the EU directive "pregnant and lactating workers". The old category "birth defects" (R47) includes only part of the reproductive risks. Consequently, we searched for supplementary lists.

As a first supplementary list for classification of reproductive effects we took the "review reprotox list" used in an earlier study. ${ }^{16} \mathrm{~A}$ list of substances with potential reproductive toxicity $(n=145)$ was compiled from four reviews of these risks. ${ }^{17-20}$ The reviews used are only a selection of all those on reproductive toxicity; other, especially more recent, reviews should be screened for supplementary substances. It is expected that in the more recent reviews more data are available on the reproductive risks to or through men. So, our list has a provisional character too; a regular update of the substances on the list and of the toxicological data is needed. As the main goal here is to make obvious how the interpretative space could be used for indications of risks (uncertainties), to give an impression of the consequences, we did not supplement the list with more recent reviews.

We also included the substances mentioned in the German MAK list as potentially fetotoxic (groups A, B, and D). ${ }^{13}$ Group A has a probable risk of fetotoxicity at the current standard; group B cannot be excluded from risk of fetotoxicity at the current standard; group D shows a trend of fetotoxicity, but a more definite categorisation based on current knowledge is not yet possible.

Finally, we included a priority list from the California Department of Health Services of substances that should be evaluated for their potential risk to reproduction or development as perceived by a scientific advisory panel, within the context of Proposition 65, the Safe Drinking Water and Toxic Enforcement Act of $1986 .{ }^{21}$ Substances on this list were first identified from publications by experts or by agencies, and were then categorised for further evaluation.

We limited ourselves here by not proposing a precautionary OEL for specific substances that are not suspected on their own, but are as a group, nor for substances with only an EU connotation of skin absorption. The 11 groups of substances are: anaesthetic gases, camphechlor, cadmium compounds, epoxyresins, fluorhydrocarbons, phthalate esters, methacrylate esters, chlorinated cyclic pesticides, glycidyl ethers, chlorobenzenes, and polychlorinated biphenyls. For substances that belong to these groups one of the strategies described later may be adopted.

It is likely that even when OELs are available, in general they have not been drafted in the light of data on reproductive toxicity. It is reasonable to presume that a toxic effect on reproduction is often one of the critical effects of these substances. ${ }^{22} 23$ Given that fact it isat least from the viewpoint of precautionrecommendable to lower current exposure standards. In the preceding article we proposed $0 \cdot 1 \mathrm{MAC}$ as a precautionary OEL for these substances, as long as no extended toxicity assessment has been done. The size of that safety factor was mentioned to be somewhat arbitrary. Therefore, here we explain an alternative method to derive a limit-also from the viewpoint of precaution. The approach elaborated here leads directly to a more specific precautionary OEL, based on the registry of toxic effects of chemical substances (RTECS) database of the National Institute for Occupational Safety and Health (NIOSH) in the United States. ${ }^{24}$ This database comprises data on 79000 substances, and $16 \%$ of them show evidence of reproductive toxicity. ${ }^{25}$ Only animal data are included.

For substances on the unlimited list one of the next three strategies should be used.

$(A)$ If inhalatory data on reproductive toxicity from the RTECS database is available, a lowest effect level (LEL) can be derived. This value should be converted with a set of safety factors to a precautionary OEL.

The database gives an overview of the available data for each substance; this includes available data on reproductive toxicity. For each study the number of experimental animals, the exposure route and duration, the type of effects, and the LEL are given. From this database we used only inhalatory studies to limit uncertainties in the extrapolation, as human occupational practice mostly involves inhalation as the primary route of entry. If animal inhalation studies of reproductive effects are found for a substance in the RTECS database, then a precautionary OEL can be derived, starting from the LEL with a simple set of three safety factors. Several extrapolations are necessary to assess the risks of reproductive toxicity for men in the workplace. Zielhuis and Van der Kreek proposed an extrapolation method for this purpose. ${ }^{26}$ They distinguished eight determining factors: ( 1 and 2) the number of animals and species examined; (3) the size of the animals; (4) the magnitude of the differences between species; (5) the seriousness of the observed health hazards; (6 and 7 ) the shape of the dose-effect curve, and the number of dose levels; and ( 8 ) the availability of human data. Zielhuis and Van der Kreek combined these eight factors into three safety factors; they preferred to offer a range for each safety factor that enables one to make an educated guess in specific cases. ${ }^{26}$ For the sake of simplicity and practicability, we used one numerical value as the safety factor, which was the average value of all these safety factors (table 1). For each substance the three safety factors relating to

Table 1 Safety factors used (derived from Zielhuis and Van der Kreek ${ }^{26}$ )

\begin{tabular}{lll}
\hline Aspects & $\begin{array}{l}\text { Safety } \\
\text { factor }^{26}\end{array}$ & $\begin{array}{l}\text { Safety factor } \\
\text { used here }\end{array}$ \\
\hline Extrapolation from LEL to NEL & $2-4$ & 3 \\
Extrapolation from animal to human, & & \\
combined with daily exposure time: & $3-10$ & 6 \\
$6-8 \mathrm{~h}$ & $1-3$ & 2 \\
$24 \mathrm{~h}$ & $5-10$ & 7 \\
Extrapolation from ST test to LT exposure: & 1 & 1 \\
ST $\rightarrow$ LT & 1 & LT $\rightarrow$ LT
\end{tabular}

LEL = lowest effect level; NEL $=$ no effect level; $S T=$ short term; LT = long term. 
Table 2 List of carcinogenic and genotoxic substances (derived from Arbeidsinspectie ${ }^{14}$ )

\begin{tabular}{|c|c|}
\hline Name & CAS number \\
\hline Acrylamide & $79-06-1$ \\
\hline Acrylnitrile & $107-13-1$ \\
\hline Aflatoxins & \\
\hline $\mathrm{AFB} 1$ & $1162-65-8$ \\
\hline AFB2 & $7220-81-7$ \\
\hline AFG1 & $1165-39-5$ \\
\hline AFG2 & 7241-98-7 \\
\hline 4-Aminobenzene & $60-09-3$ \\
\hline o-Aminoazoazotoluene & $97-56-3$ \\
\hline $\begin{array}{l}\text { 4-Aminobiphenyl (+ salts) } \\
\text { o-Anisidine }\end{array}$ & $\begin{array}{l}92-67-1 \\
90-04-0\end{array}$ \\
\hline Arsenic trioxide & $1327-53-3$ \\
\hline Arsenic acid (+ salts) & $7778-39-4$ \\
\hline Arsenic pentoxide & $1303-28-2$ \\
\hline Asbestos & $1332-21-4$ \\
\hline Auramine & $492-80-8$ \\
\hline Azaserine & $115-02-6$ \\
\hline Azathiopine & $446-86-6$ \\
\hline Aziridine & $151-56-4$ \\
\hline Benzene & $71-43-2$ \\
\hline Benzidine (+ salts) & $92-87-5$ \\
\hline Benz(a)anthracene & $56-55-3$ \\
\hline Benz(a)pyrene & $50-32-8$ \\
\hline Benz (b) fluoranthene & $205-99-2$ \\
\hline Benz(j)fluoranthene & $205-82-3$ \\
\hline Benz (k) fluoranthene & $207-08-9$ \\
\hline Benztrichloride & $98-07-7$ \\
\hline Beryllium & $7440-41-7$ \\
\hline oro-)methylether & $542-88-1$ \\
\hline Bleomycine & $11056-06-7$ \\
\hline 1,3-Butadiene & $106-99-0$ \\
\hline Bisulfan & $55-98-1$ \\
\hline $2-(p$-Tert-butylphen & \\
\hline isopropyl-2-chloroethylsul & $140-57-8$ \\
\hline$\beta$-Butyrolactone & $3068-88-0$ \\
\hline Cadmium chloride & $10108-64-2$ \\
\hline Cadmium oxide & $1306-19-0$ \\
\hline Cadmium st & $10124-36-4$ \\
\hline Calcium chromate & $13765-19-0$ \\
\hline Captafol & $2425-06-1$ \\
\hline Carbadox & $6804-07-5$ \\
\hline Carmustine & $145-93-8$ \\
\hline Chlorambucil & $305-03-3$ \\
\hline Chlormethine $\mathrm{N}$-oxide & $126-85-2$ \\
\hline Chlormethyl methylether & $107-30-2$ \\
\hline Chlornaphazine & 494-03-1 \\
\hline 4-Chlor-o-phenylenediamine & $95-83-0$ \\
\hline Calcium chromate & $13765-19-0$ \\
\hline Chromo III chromate & $24613-89-6$ \\
\hline Chromium trioxide & $1333-82-0$ \\
\hline Strontium chromate & $7789-06-2$ \\
\hline Cisplatine & $15663-27-1$ \\
\hline Citrus red 2 & $6358-53-8$ \\
\hline$p$-Cresidine & $120-71-8$ \\
\hline Cycasine & $14901-08-7$ \\
\hline Cyclophosphamide & $50-1$ \\
\hline Dacarbazine & $4342-03-4$ \\
\hline Daunorubicidine & $20830-81-3$ \\
\hline $\mathrm{N}, \mathrm{N}^{\prime}$-diacetylbenzidine & 613 \\
\hline 2,4-Diamino-anisolsulphate & $39156-41-7$ \\
\hline $4,4^{\prime}$-Diaminodiphenylether & $101-80-4$ \\
\hline 2,4-Diaminotoluene & $95-80-7$ \\
\hline o-Dianisidine (+ salts) & 119 \\
\hline Diazomethane & $334-88-3$ \\
\hline $\operatorname{Dibenz}(\mathrm{a}, \mathrm{h}) \mathrm{acr}$ & 226 \\
\hline Dibenz $(\mathrm{a}, \mathrm{h})$ anthracene & $53-70-3$ \\
\hline Dibenz $(\mathrm{a}, \mathrm{h})$ pyrene & $189-64-0$ \\
\hline Dibenz $(a, i)$ pyrene & $189-55-9$ \\
\hline 7H-Dibenz(c, & $194-59-2$ \\
\hline 1,2-Dibromo-3-chloropropane & $96-12-8$ \\
\hline 1,2-Dibromoethane & $106-93-4$ \\
\hline 3,3'-Dichlor-benzidine (+ salts) & $91-94-1$ \\
\hline 3,3'-Dichlor-4,4'-diamino- & \\
\hline diphenylether & 6-8 \\
\hline 1,4-Dichlorbut-2-ene & 764 \\
\hline 1,2-Dichlorethane & 107 \\
\hline 1,3-Dichlor-2-propanol & $96-2$ \\
\hline Diethylsulphate & $64-67-5$ \\
\hline Diglycidyl resorcinolether & $101-90-6$ \\
\hline ylaminoazobenzene & \\
\hline arbamoylchloride & 79 \\
\hline 1,1-Dimethyl hydrazine & $57-14-7$ \\
\hline 1,2-Dimethyl hydrazine & $540-73-8$ \\
\hline Dimethyl sulphate & $77-78-1$ \\
\hline Dimethyl sulphamoylchloride & $13360-57-1$ \\
\hline Dinickel trioxide & $1314-06-3$ \\
\hline 1,6-Dinitropyrene & $42397-64-8$ \\
\hline 1,8-Dinitropyrene & 42397-65-9 \\
\hline Direct black 38 & $1937-37-7$ \\
\hline Direct blue 6 & $2602-46-2$ \\
\hline Direct brown 95 & $16071-86-6$ \\
\hline Disperse blue & $2475-45-8$ \\
\hline Doxorubicine & $23214-92-8$ \\
\hline Epichlorhydrin & $106-89-8$ \\
\hline Enonite & 66733-21-9 \\
\hline Ethylene oxide & $75-21-8$ \\
\hline Ethylmethane sulphate & $62-50-0$ \\
\hline
\end{tabular}

aspects 1,2 , and 3 have to be multiplied. This leads to an overall safety factor (OSF) of 6 , 18,42 , or 126 . If the exposure time differs from those times mentioned in table 1 , an adapted safety factor can be set.

$(B)$ If no RTECS inhalatory data are available, 0.1 MAC should be used as a precautionary OEL.

(C) If no MAC is available, $0.1 \mathrm{mg} / \mathrm{m}^{3}$ should be the precautionary OEL. This corresponds to the approach for the category "carcinogenic or genotoxic substances".

\section{Results}

CARCINOGENIC OR GENOTOXIC SUBSTANCES

Table 2 summarises the 190 substances that were classified as carcinogenic or genotoxic. ${ }^{14}$

SUBSTANCES WITH EFFECTS ON REPRODUCTION

Table 3 shows the 156 substances for which indications of reproductive toxicity were found, and their proposed precautionary OELs. The availability of inhalatory studies indicating reproductive toxicity in the RTECS database (February 1993) ${ }^{24}$ was checked: for 54 substances inhalatory studies are available (category $A$ ); for 59 substances with a MAC, no inhalatory studies are available (category $B$ ), and of these, 40 substances had data from other exposure routes; for 43 substances without a MAC, no inhalatory studies were available (category $C$ ), and of these, 24 substances had data from other exposure routes.

For the substances belonging to category $A$, table 3 shows the derivation of a precautionary OEL, starting from the LEL and applying an integrated overall safety factor. If the calculated value was lower than $1 / 10$ of the current MAC, this value was chosen as the precautionary OEL. These values are printed in bold. For comparison of the precautionary OEL, the current MAC values are listed as well. Fourteen of the 54 calculated precautionary OELs exceed $0 \cdot 1 \mathrm{MAC}$. In those cases $0.1 \mathrm{MAC}$ is chosen as the precautionary OEL. For lead compounds no exposure is obligatory according to the EU directive "pregnant and lactating women".

\section{Discussion and conclusions}

Current attitudes for setting standards combines risk regulation and risk acceptance. In contrast, an approach that judges exposures from the perspective of the precautionary principle fits into the risk avoidance attitude. The strategy for setting standards elaborated here-aimed at preventing serious harmtakes a pragmatic approach: it combines risk avoidance and risk regulation as it starts with substantial indications of threatening harm in policy documents or in peer reviewed literature. It follows that no precautionary OEL is proposed for those substances that are as yet not suspected of causing serious harm and do not have a MAC. A stricter application of pre- 
caution would lead to the principle that every exposure to a substance should be zero, unless it is shown that a specified exposure to that substance will not be harmful. Nevertheless, our approach is stricter than the current strategy for setting standards. Also, we provide a more tailor made procedure than the uniform precautionary approach - as described in the preceding article ${ }^{1}$-in which for all substances the same safety factor of 10 is used (the "factor 10 method") as long as no comprehensive assessment has been done in which all studies are critically evaluated according to a set of criteria (the "critical health based recommended OEL method"). ${ }^{27}$ As 14 of the 54 calculated precautionary OELs exceed $0 \cdot 1$ $M A C$, it can be questioned whether the generic safety factor, as proposed in the preceding article, ${ }^{1}$ is cautious enough for most of the chemical substances, as long as no extensive toxicity assessment has been done. It probably is for those with no indications of reproductive toxicity but not for substances for which indications are evident.

We considered the extent of the EU lists for both categories of substances to be rather limited. For that reason we added other substances from science and policy sources. Although the EU criteria for classification of reproductive substances were broadened recently, until now this has led to only a short list of substances with suspected or proved reproductive toxicity. ${ }^{28}$ Classification was based on epidemiological and animal studies. Distinction was made between three categories, depending on the strength of evidence of reproductive risks. In the Nordic countries a comparable classification system was developed, but there too it did not lead to a longer list of substances..$^{29} 30 \mathrm{We}$ therefore combined the EU list with a list based on four critical reviews; the list of suspected fetotoxic agents, derived from the German MAK list; and the Californian list that contained substances with potential toxic effects on reproduction.

For practical reasons, we chose only inhalatory studies. The method would have been improved if the available reproductive studies with exposure routes other than inhalatory had been also taken into account. The same holds for the safety factors used. Although Zielhuis and Van der Kreek offered a range for each safety factor, ${ }^{26}$ we chose for the sake of simplicity to use the average value. Instead of a range for each factor it would be preferable to enlarge the number of safety factors-for example, by using the eight original elements of the three safety factors mentioned by Zielhuis and Van der Kreek, or by using the eight elements of the safety factor proposed in the "critical health based recommended OEL method", ${ }^{27}$ which are somewhat different from those of Zielhuis and Van der Kreek. ${ }^{26}$

As our method uses the LELs as the reference points without critical evaluation of the study, it could be considered that we evaluated in more detail the quality of the studies that showed LELs much lower-for example, a factor of 100 lower-compared with other LELs. Such an approach may prevent a low quality study with a very low limit needlessly leading to a very low precautionary OEL.

The method can also be improved by deriving precautionary OELs from data that supplement the RTECS database. The inclusion of human data would contribute substantially to such an improvement. The on line database TOX-ALL may also be of help in this respect. ${ }^{31}$ It is clear that all those improvements in validity take time, and may be impractical, as this method has to be applied by such bodies as occupational health and safety services.

A calculation that only takes into account the LEL for reproductive effects may lead in specific cases to an inadequate generic precautionary OEL. Londo ${ }^{23}$ compared 42 substances from the current Dutch MAC list of which LELs for reproductive effects were available in the RTECS database, and at least the LELs for one other organ system; reproductive effect was critical in 27 of those substances, and in seven was one of the critical effects; in eight substances other effects were critical. So to broaden the method to other effects could be considered.

A major point of contention raised by our approach concerns the extrapolation of safety factors. Internationally, no agreement exists on a safety factor, whether to use a rigid or a more variable one. The World Health Organisation usually takes a rigid safety factor of 100 , consisting of a factor of 10 for the differences between species, and another factor of 10 for the differences within species. In The Netherlands, the scientific advisory board has chosen a more variable safety factor, ${ }^{32}$ based essentially on the study by Zielhuis and Van der Kreek. ${ }^{26}$ The discussion gained new momentum in the Dutch Expert Group on Occupational Standards, which prepares health based guidelines for workplace exposure standards ${ }^{33}$; it seems that in this discussion the principle of variability was still being followed. Safety factors are also a subject of discussion in the European Scientific Expert Group when drafting guidelines for workplace exposure. It seems that this group also prefers variable safety factors. ${ }^{35}$ In view of the different approaches to the use of safety factors we have chosen to present both the LELs, as indicated in RTECS, and the overall safety factor, as used by us.

In the future, knowledge will increase, presumably leading to lists that are more extended, more limited, but better underpinned. Moreover, our approach elaborated the situation for single substances. Consequently, the groups of substances that were mentioned as suspected of being carcinogenic or having toxic effects on reproduction are not taken into account in this method. One may choose the separate substances belonging to those groups from the three strategies as described here.

Implementation of the proposed precautionary OELs can strongly reduce workplace exposure to substances that may lead to serious or irreversible harm. Because implementation may require major changes in company 
Table 3 List and precautionary occupational exposure limits (OELs) of single substances with reproductive toxicity not designated as carcinogenic or genotoxi

\begin{tabular}{|c|c|c|c|c|c|c|c|}
\hline Name & $C A S$ number & $\begin{array}{l}M A C 1994 \\
\left(m g / m^{3}\right)^{35}\end{array}$ & $\begin{array}{l}\text { Studies in } \\
\text { RTECS† (n) }\end{array}$ & $\begin{array}{l}L E L \dagger \\
\left(\mathrm{mg} / \mathrm{m}^{3}\right)\end{array}$ & OSFt & Category $\ddagger$ & $\begin{array}{l}\text { Precautionary } \\
O E L \oint\left(\mathrm{mg} / \mathrm{m}^{3}\right)\end{array}$ \\
\hline Acetaldehyde $^{13}$ & $75-07-0$ & 180 & $-(+)$ & & & B & 18 \\
\hline Actelic $^{19}$ & $29232-93-7$ & - & - & & & $\mathrm{C}$ & $0 \cdot 1$ \\
\hline Aldrin $^{1921}$ & $309-00-2$ & $0 \cdot 25$ & - & & & B & 0.025 \\
\hline Aluminium chloride ${ }^{19}$ & $7446-70-0$ & - & $-(+)$ & & & C & $0 \cdot 1$ \\
\hline Aniline $^{131719}$ & $62-53-3$ & 1 & $-(+)$ & & & B & $0 \cdot 1$ \\
\hline Antracol ${ }^{19}$ & $12071-83-9$ & - & $-(+)$ & & & $\mathrm{C}$ & $0 \cdot 1$ \\
\hline Arsenic, inorganic ${ }^{21}$ & $744-03-82$ & 0.05 & - & & & B & 0.005 \\
\hline Atrazine $^{19}$ & $1912-24-9$ & 5 & $-(+)$ & & & B & 0.5 \\
\hline 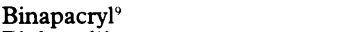 & $485-31-4$ & - & - & & & $\mathrm{C}$ & $0 \cdot 1$ \\
\hline Biphenyl ${ }^{13}$ & $92-52-4$ & 1 & - & & & B & $0 \cdot 1$ \\
\hline Bisphenol $\mathrm{A}^{19}$ & $80-05-7$ & - & $-(+)$ & & & $\mathrm{C}$ & $0 \cdot 1$ \\
\hline Boric acid ${ }^{1921}$ & $10043-35-3$ & - & 1 & $9 \cdot 6 / 4 \mathrm{~h}$ & 30 & A & $0 \cdot 3$ \\
\hline Boron $^{17}$ & $7440-42-8$ & - & - & & & $\mathrm{C}$ & $0 \cdot 1$ \\
\hline Bromide $^{19}$ & - & - & - & & & $\mathrm{C}$ & $0 \cdot 1$ \\
\hline n-Butanol ${ }^{13}$ & $71-36-3$ & 150 & 2 & $6000 \mathrm{ppm} / 7 \mathrm{~h}$ & 126 & A & 15 \\
\hline Butylacrylate $^{1319}$ & $141-32-2$ & 55 & 1 & $135 \mathrm{ppm} / 6 \mathrm{~h}$ & 42 & A & $5 \cdot 5$ \\
\hline Cadmium $^{21}$ & $7440-43-9$ & 0.02 & $-(+)$ & & & B & $0 \cdot 002$ \\
\hline Caprolactam $^{1819}$ & $105-60-2$ & 20 & 1 & $125 / 24 \mathrm{~h}$ & 42 & A & 2 \\
\hline Captan ${ }^{19}$ & $133-06-2$ & 5 & $-(+)$ & & & B & 0.5 \\
\hline${\text { Carbaryl }{ }^{19}}^{19}$ & $63-25-2$ & 5 & $-(+)$ & & & B & 0.5 \\
\hline Carbon dioxide ${ }^{1921}$ & $124-38-9$ & 9000 & 6 & $55 \mathrm{pph} / 2 \mathrm{~h}$ & 315 & A & 900 \\
\hline Carbon disulfide ${ }^{91321}$ & $75-15-0$ & 60 & 8 & $0.03 / 8 \mathrm{~h}$ & 126 & A & $0 \cdot 0002$ \\
\hline Carbon monoxide ${ }^{131719}$ & $630-08-0$ & 29 & 8 & $1 / 24 \mathrm{~h}$ & 42 & A & $0 \cdot 02$ \\
\hline Carbon tetrachloride 131921 & $56-23-5$ & $12 \cdot 6$ & 2 & $250 \mathrm{ppm} / 8 \mathrm{~h}$ & 126 & A & $1 \cdot 3$ \\
\hline Chlordane ${ }^{21}$ & $57-74-9$ & 0.5 & $-(+)$ & & & $\mathbf{B}$ & 0.05 \\
\hline Chlordecone ${ }^{1719}$ & $143-50-0$ & - & $-(+)$ & & & $\mathrm{C}$ & $0 \cdot 1$ \\
\hline Chlormethane $^{13}$ & $74-87-3$ & 105 & 7 & $500 \mathrm{ppm} / 6 \mathrm{~h}$ & 126 & A & 9 \\
\hline \multicolumn{8}{|l|}{ 5-Chlor-2-methyl-2,3- } \\
\hline Chlorodifluormethane $^{17}$ & $75-45-6$ & 3600 & 1 & $50000 \mathrm{ppm} / 5 \mathrm{~h}$ & 210 & A & 360 \\
\hline Chloroform $(3,5,6,7)^{13171921}$ & $67-66-3$ & 5 & 6 & $30 \mathrm{ppm} / 7 \mathrm{~h}$ & 126 & A & $0 \cdot 5$ \\
\hline Chloroprene ${ }^{13171920}$ & $126-99-8$ & 36 & 6 & $0 \cdot 15 / 24 \mathrm{~h}$ & 6 & A & $0 \cdot 025$ \\
\hline Copper $^{19}$ & $7440-50-8$ & $0 \cdot 2$ & $-(+)$ & & & $\mathrm{B}$ & 0.02 \\
\hline Copper sulphate ${ }^{21}$ & $7758-98-7$ & - & $-(+)$ & & & C & $0 \cdot 1$ \\
\hline Cyclohexanol $^{20}$ & $108-93-0$ & 1 & $-(+)$ & & & B & $0 \cdot 1$ \\
\hline Cyclohexylamine $^{13}$ & $108-91-8$ & 40 & $-(+)$ & & & B & 4 \\
\hline $2,4-\mathrm{D}^{19}$ & $94-75-7$ & 10 & $-(+)$ & & & B & 1 \\
\hline 2,4-D Butyl ester ${ }^{21}$ & $94-80-4$ & - & - & & & C & $0 \cdot 1$ \\
\hline DDT $^{1921}$ & $50-29-3$ & 1 & $-(+)$ & & & B & $0 \cdot 1$ \\
\hline DDVP $^{19}$ & $62-73-7$ & - & 1 & $4 / 23 h$ & 42 & A & $0 \cdot 1$ \\
\hline Demeton $^{19}$ & $8065-48-3$ & $0 \cdot 1$ & $-(+)$ & & & B & 0.01 \\
\hline 1,2-Diaminoethane ${ }^{13}$ & $107-15-3$ & 25 & $-(+)$ & & & B & $2 \cdot 5$ \\
\hline 1,1-Dichlorethane ${ }^{13}$ & $75-34-3$ & 400 & 1 & $6000 \mathrm{ppm} / 7 \mathrm{~h}$ & 126 & A & 40 \\
\hline 1,1-Dichlorethylene ${ }^{21}$ & $75-35-4$ & - & 3 & $55 \mathrm{ppm} / 6 \mathrm{~h}$ & 126 & A & $0.4 \mathrm{ppm}$ \\
\hline Dichlormethane ${ }^{1317-1921}$ & $75-09-2$ & 350 & 2 & $1250 \mathrm{ppm} / 7 \mathrm{~h}$ & 126 & A & $34 \times 2-2$ \\
\hline 1,2-Dichlorpropane ${ }^{21}$ & $78-87-5$ & 350 & - & & & B & 35 \\
\hline Dieldrin $^{20}$ & $60-57-1$ & $0 \cdot 25$ & $-(+)$ & & & $\mathbf{B}$ & 0.025 \\
\hline Diethylether $^{13}$ & $60-29-7$ & 1200 & - & & & $\mathbf{B}$ & 120 \\
\hline Diphenylhydrazine $^{19}$ & $122-66-7$ & - & - & & & $\mathrm{C}$ & $0 \cdot 1$ \\
\hline Dipholatan $^{19}$ & $2425-06-1$ & - & $-(+)$ & & & $\mathrm{C}$ & $0 \cdot 1$ \\
\hline 3-(Dimethylamino-) & & & & & & & \\
\hline propionitrile $^{19}$ & $1738-25-6$ & - & - & & & C & $0 \cdot 1$ \\
\hline 1,4-Hydroxybenzene ${ }^{13}$ & $123-31-9$ & - & $-(+)$ & & & $\mathrm{C}$ & $0 \cdot 1$ \\
\hline Dimethyl acetamide ${ }^{19}$ & $127-19-5$ & 35 & 4 & $281 \mathrm{ppm} / 6 \mathrm{~h}$ & 126 & A & $3 \cdot 5$ \\
\hline Dimethyl benzanthracene $^{19}$ & $57-97-6$ & - & $-(+)$ & & & $\mathrm{C}$ & $0 \cdot 1$ \\
\hline Dimethyl ether ${ }^{13}$ & $115-10-6$ & 1910 & - & & & B & 190 \\
\hline Dimethyl formamide ${ }^{9131920}$ & $68-12-2$ & 30 & 2 & $4 / 4 \mathrm{~h}$ & 210 & A & 0.02 \\
\hline Dinitrotoluene $^{19}$ & $25321-14-6$ & 1.5 & $-(+)$ & & & B & $0 \cdot 15$ \\
\hline Dinoseb $^{9}$ & $88-85-7$ & - & $-(+)$ & & & C & $0 \cdot 1$ \\
\hline Dinoterp ${ }^{9}$ & $1420-07-01$ & - & - & & & C & $0 \cdot 1$ \\
\hline 1,4-Dioxan ${ }^{13}$ & $123-91-1$ & 40 & $-(+)$ & & & B & 4 \\
\hline Diquat $^{19}$ & $2764-72-9$ & 0.5 & $-(+)$ & & & B & 0.05 \\
\hline Endrin $^{1921}$ & $72-20-8$ & $0 \cdot 1$ & $-(+)$ & & & B & 0.01 \\
\hline Ethanol $^{13}$ & $64-17-5$ & 1900 & 1 & $20000 \mathrm{ppm} / 7 \mathrm{~h}$ & 126 & A & 190 \\
\hline Ethoxyethanol ${ }^{91319}$ & $110-80-5$ & 19 & 9 & $10 \mathrm{ppm} / 6 \mathrm{~h}$ & 126 & A & $0 \cdot 3$ \\
\hline Ethoxyethyl acetate ${ }^{9131921}$ & $111-15-9$ & 27 & 9 & $50 \mathrm{ppm} / 6 \mathrm{~h}$ & 126 & A & 2 \\
\hline Ethyl acrylate $^{13}$ & $140-88-5$ & 20 & - & & & B & 2 \\
\hline Ethyl benzene $^{1319}$ & $100-41-4$ & 215 & 8 & $96 \mathrm{ppm} / 7 \mathrm{~h}$ & 126 & $\bar{A}$ & 3 \\
\hline Ethyl formate ${ }^{13}$ & $109-94-4$ & 300 & - & & & $\mathrm{B}$ & 30 \\
\hline $\begin{array}{l}\text { 2-Ethylhexyl-3,5-bis }(1,1- \\
\text { dimethylethyl)-4-hydroxyfenyl }\end{array}$ & & & & & & & \\
\hline methylthioacetate ${ }^{9}$ & $80387-97-9$ & - & $-(+)$ & & & $\mathrm{C}$ & $0 \cdot 1$ \\
\hline Ethylene chlorhydrine $^{19}$ & $107-07-3$ & 3 & $-(+)$ & & & B & $0 \cdot 3$ \\
\hline Ethylene dibromide $^{21}$ & $106-93-4$ & 155 & 9 & $39 \mathrm{ppm} / 7 \mathrm{~h}$ & 126 & A & $2 \cdot 4$ \\
\hline Ethylene glycol ${ }^{1920}$ & $107-21-1$ & 26 & $-(+)$ & & & B & $2 \cdot 6$ \\
\hline Ethylene thiourea 1921 & $96-45-7$ & - & 2 & $27 / 3 \mathrm{~h}$ & 210 & $\overline{\mathrm{A}}$ & $0 \cdot 1$ \\
\hline Phenol $^{1921}$ & $108-95-2$ & 19 & $-(+)$ & & & B & 1.9 \\
\hline Fenthion $^{19}$ & $55-38-9$ & $0 \cdot 1$ & $-(+)$ & & & B & 0.01 \\
\hline Folpet $^{1921}$ & $133-07-3$ & - & 1 & 491/4h & 210 & A & 2 \\
\hline Formaldehyde ${ }^{171921}$ & $50-00-0$ & 1.5 & 6 & $0.05 / 4 \mathrm{~h}$ & 210 & A & 0.0002 \\
\hline Formamide $^{19-21}$ & $75-12-7$ & 30 & $-(+)$ & & & B & 3 \\
\hline Fundazol $^{19}$ & - & - & $-(+)$ & & & $\mathrm{C}$ & $0 \cdot 1$ \\
\hline Gallium $^{19}$ & $7440-55-3$ & - & - & & & C & $0 \cdot 1$ \\
\hline Halothane $e^{1320}$ & $151-67-7$ & 40 & 12 & $10 \mathrm{ppm} / 8 \mathrm{~h}$ & 126 & A & 0.6 \\
\hline Heptachlor ${ }^{21}$ & $76-44-8$ & 0.5 & - & & & B & 0.05 \\
\hline Hexachlorcyclohexane ${ }^{1920}$ & $58-89-9$ & $0 \cdot 5$ & - & & & B & 0.05 \\
\hline Hexachlorophene ${ }^{19}$ & $70-30-4$ & - & 1 & $33 \cdot 5 / 24 h$ & 42 & A & $0 \cdot 8$ \\
\hline $\mathrm{n}-\mathrm{Hexane}^{21}$ & $110-54-3$ & 90 & 3 & $1000 \mathrm{ppm} / 6 \mathrm{~h}$ & 126 & A & 9 \\
\hline Isopropyl alcoho ${ }^{19} 13$ & $67-63-0$ & 980 & 3 & $8000 / 7 \mathrm{~h}$ & 126 & A & 64 \\
\hline
\end{tabular}

* - (+) Only data with exposure routes other than inhalatory are available in the registry of toxic effects of chemical substances (RTECS) data base; $\overline{-}=$ no reproductive toxicity data available in RTECS.

TLEL = lowest effect level; OSF = overall safety factor. The LEL and the OSF are only given if RTECS inhalation reproductive toxicity data are available. If the OSF is italicised, an adapted extrapolation factor is used for variable exposure times.

$\ddagger A=R T E C S$ inhalatory reproductive toxicity studies available; $B=$ no RTECS inhalatory reproductive toxicity studies available, Dutch MAC (1994) ${ }^{35}$ available; $C=$ no RTECS inhalatory reproductive toxicity studies available, no Dutch MAC $(1994)^{35}$ available.

CCalculated precautionary OELs are in bold; $0 \cdot 1$ of the MAC is the proposed precautionary OEL for calculated values $>0 \cdot 1$ of the MAC; these values are in italics. CAS = chemical abstract service. 
Table 3 continued from page 310

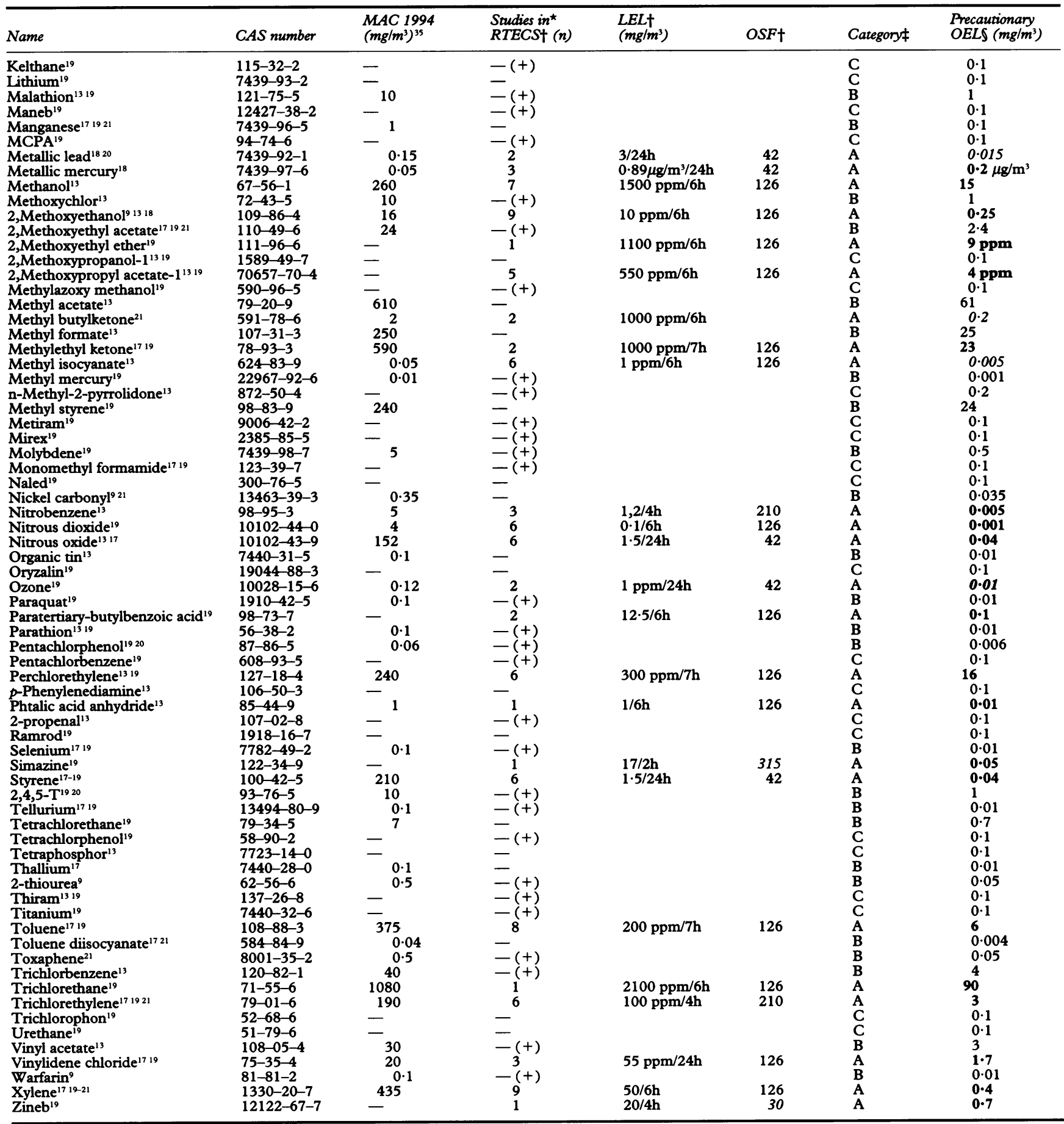

practices it would be best to develop a time frame for the gradual phasing in of precautionary OELs.

The proposed strategy is written from the EU perspective of setting standards and from the EU directives concerning carcinogenic and toxic substances with reproductive toxicity. It is not meant as an alternative to the current EU strategy for setting standards but as a means to adapt and supplement the current, partly very dated, standards easily in a short period of time more towards risk-avoidance, and to supplement the list of standards with substances for which at least indications of carcinogenic or reproductive risks exist. Outside Europe, similar discussions are going on. At the UNCED in Rio de Janeiro in 1992 the precautionary principle was adopted worldwide. With our approach we hope to stimulate international discussion about the way in which this international agreement could be made operational, especially in setting standards for occupational health and safety purposes.

We thank Drs M J Koene from the Dutch Institute for the Working Environment and J P van der Sluys from the Department of Science, Technology, and Society of Utrecht University for their valuable suggestions.

1 Stijkel A, van Dijk F. Developments in reproductive risk mane Occup Environ Med 1995;52:294-303.

2 Douglas M, Wildawsky A. Risk and culture. An essay on the selection of technical and environmental dangers. Berkeley: University of California Press, 1982.

3 Sabatier P. Knowledge, policy-oriented learning and policy change. An advocacy framework. Knowledge: Creation, Diffusion, Utilization 1987;8:649-72. 
4 Bus J, Posthuma J, Broekhuizen PC van, Stijkel A, Ulenbelt P. $M A C$-waarden op de arbeidsplaats ( $M A C$ values at the workplace). Alphen aan den Rijn: Samson HD Tienk Willink, 1992:34-41.

5 Landelijk Milieu Overleg (LMO). Brief aan de Minister van Sociale Zaken en Werkgelegenheid betreffende de EGrichtlijn zwangeren in relatie tot milieu en gezondheid (Letter to the Minister of Social Affairs and Employment concerning the EC directive pregnant workers). Utrecht: LMO, 1992. (U-LMO-92-107.)

6 Landelijk Milieu Overleg (LMO). Brief aan de Minister van Sociale Zaken en Werkgelegenheid betreffende verlaging dioxine norm en ontwerpbesluit zwangere werkneemsters dioxine norm en ontwerpbesluit zwangere werkneemsters cotter the Minister of Social Afrais and Employment concerning lowering the dioxin norm and the concept (U-LMO-93-161.)

7 United Nations conference on environment and development (UNCED). Declaration of Rio. Rio de Janeiro, Brazil: UN 1992. (Principle 15.)

8 Commission of the European Communities (CEC). Directive of the Council concerning the classification of hazardous substances. Brussels: CEC 1967. (67/548/EEC.)

9 Commission of the European Communities (CEC). Directive of the Council concerning the eighteenth amendment to Directive 67/548/EEC. Brussels: CEC, 1993. (93/21/EEC.)

10 Commission of the European Communities (CEC). Directive of the Council concerning the protection against the risks of exposure to carcinogenic substances at work. Brussels: CEC, 1990. (90/394/EEC.)

11 Commission of the European Communities (CEC). Directive of the Council concerning the protection at work of pregnant women or women who have recently given birth. pregnant women or women who have

12 Arboraad. Advies inzake grenswaarden voor genotoxisch carcinogene stoffen (Advice concerning standard setting for genotoxic carcinogenic substances). Zoetermeer: Arboraad, 1992

13 Deutsche Forshungsgemeinschaft. $M A K$ - und BAT-werte Liste (MAC- and TRC-value lists). Weinheim, 1994. (Mitteilung 30.)

14 Arbeidsinspectie. Werken met kankerverwekkende stoffen en processen (Working with carcinogenic substances and processes). The Hague: Ministry of Social Affairs and Employment, 1994:187.

15 Dijk-Looijaard AM van. Herziening normen drinkwaterbesluit (Readjustment water supply directive concerning waterbesluit (Readjustment water supply directive concerning
guidelines). Niewegein: KIWA, 1993. (SWO93.340.)

16 Stijkel A. Een reprotoxinstrument (A reprotox instrument) The Hague: Ministry of Social Affairs and Employment, The Hague: Ministry of Social Affairs and Empl

17 Barlow SM, Sullivan FM. Reproductive hazards of industrial chemicals. London: Academic Press, 1982.

18 Zielhuis RL, Stijkel A, Verberk MM, Poel-Bot M van de. Health risks to female workers in occupational exposure to chemical agents. Int Arch Occup Environ Health 1984;suppl: 120

19 Fletcher AC. Reproductive hazards of work. Manchester Equal Opportunities Commission, 1985.

20 Koeter HBWM, Dreef van der Meulen HC, Stijkel A Zielhuis RL. Schadelijke effecten van stoffen op voortplanting en nageslacht anders dan via de inwerking op het erfelijk materiaal, indien deze bekend is. Een literatuurstudie. (Toxic effects of substances on reproduction and progeny. A literature study). The Hague: Ministry of Social Affairs and Employment, Directorate General of

1 Donald JM, Monserrat LE, Hooper K, Book SA, Chernoff GF. Prioritizing candidate reproductive/developmental toxicants for evaluation. Reprod Toxicol 1992;6:99-108.

22 Koeter HWBM. Relevance of parameters related to fertility and reproduction in toxicity testing. $\mathrm{Am} \mathcal{f}$ Ind $\mathrm{Med}$ 1983;4:81-6.

23 Londo $\mathrm{M}$. Implementatie van het voorzorgprincipe in de $M A C$-waarden: speurtocht naar het kritisch effect (Implementation of the precautionary principle in the $M A C$ values; search for the critical effect). Utrecht: Utrecht University, Department of Science, Technology, and Society, 1994.

24 National Institute for Occupational Safety and Health. CD-rom database: registry of toxic effects of chemical substances (RTECS) update. Cincinnati: NIOSH, 1993.

25 Paul M, Welch L. Improving education and resources for health care providers. Environ Health Perspect 1993; 101(suppl 2): 191-7.

26 Zielhuis RL, Kreek FW van der. The use of a safety factor in setting health based permissible levels for occupational exposure. I: a proposal; II: comparison of extrapolated and published permissible standards. Int Arch Occup Environ Health 1979;42:203-15.

27 Stijkel A, Verberk MM. A proposal for systematically drafting health-based recommended occupational exposure limits (HBR-OEL) illustrated on reproductive toxicity. In Stijkel A On managing reproductive risks of occupational exposure to chemicals. Amsterdam: University occupational exposure to chemicals. Amsterdam. Uniseris preparation.) preparation.)

Sullivan F. Occupational hazards and reproduction. Third international NIVA course. Lecture: EU criteria. Turkku, 10 November 1994. F Occup Med 1995; (in press).

29 Taskinen H. Prevention of reproductive health hazards at work. Scand $f$ Work Environ Health 1992;18(suppl 2):27-9.

30 Taskinen $H$. Occupational hazards and reproduction. Third international NIVA course. Lecture: Nordic criteria. Turkku, 10 November 1994. f Occup Med 1995; (in press).

31 Stijkel A. Vergelijkend warenonderzoek databestanden mbt reprotox (Comparison of databases concerning reproductive risks) internal report. Amsterdam: University of risks) internal report. Amsterdam:

32 Gezondheidsraad. Advies inzake uitgangspunten voor normstelling (Advice concerning starting points for standard setting). The Hague: Gezondheidsraad, 1985.

33 Mik G de. De advieswaarden: wikken en wegen (The guidelines: a weighing process). Tijdschrift voor Sociale Gezondheidszorg 1993;71:120-1.

34 Commission of the European Commission (CEC). Health and safety, occupational exposure limits, criteria documents. Guidance note on the content and layout. Brussels: Health and Safety Directorate, 1992.

35 Arbeidsinspectie. De nationale MAC-lijst (The national $M A C$-list). The Hague: Ministry of Social Affairs and Employment, Directorate General of Labour, 1994:145.

\section{Correspondence and editorials}

Occupational and Environmental Medicine welcomes correspondence relating to any of the material appearing in the journal. Results from preliminary or small scale studies may also be published in the correspondence column if this seems appropriate. Letters should be not more than 500 words in length and contain a minimum of references. Tables and figures should be kept to an absolute minimum. Letters are accepted on the understanding that they may be subject to editorial revision and shortening.

The journal also publishes editorials which are normally specially commissioned. The Editor welcomes suggestions regarding suitable topics; those wishing to submit an editorial, however, should do so only after discussion with the Editor. 